\title{
Thermal Stability of Austenite Retained in Bainitic Steels
}

\author{
A. Saha Podder and H. K. D. H. Bhadeshia \\ University of Cambridge \\ Materials Science and Metallurgy \\ Pembroke Street, Cambridge CB2 3QZ, U. K.
}

\begin{abstract}
Steels with a microstructure consisting of a mixture of bainitic ferrite and carbon-enriched retained austenite are of interest in a variety of commercial applications because they have been shown to exhibit good combinations of strength, toughness and ductility. However, their use at temperatures moderately above ambient requires a knowledge of the thermal stability of the austenite. The changes that occur during the tempering of a mixture of bainitic ferrite, carbon-enriched retained austenite and martensite have been characterised. An analysis of the volume change due to transformation shows that it is possible to distinguish the decomposition of austenite from the tempering of martensite. The nature of the carbides that form during the heat treatment is discussed as are the implications on the development of mathematical models accounting for calculating the strain during austenite decomposition and martensite tempering. It is found that the early stages of tempering reactions where the austenite content is not greatly reduced, can dramatically influence the stability of the austenite as it is cooled to ambient temperature.
\end{abstract}

\section{Introduction}

It is known that in a tensile test, the onset of plastic instability can be delayed by the presence of austenite which gradually undergoes martensitic transformation during the course of elongation. The resulting transformation-induced plasticity is known at the TRIP effect $[1,2]$. A cheap way of introducing austenite in the microstructure is by preventing the precipitation of iron carbides during the bainite transformation $[3,4]$. The carbon that is partitioned from bainitic ferrite then stabilises the residual austenite. Silicon and aluminium additions can achieve this by affecting the chemical driving force for the precipitation of cementite from austenite [5]. Many commercially successful steel concepts have been developed based on such mixed microstructures of bainitic ferrite and carbon-enriched retained austenite, reviewed in [6-10].

The microstructure consisting of bainitic ferrite and carbon-enriched retained austenite is not thermodynamically stable because the reaction stops when the latter phase reaches approximately 
a composition defined by the $T_{0}$ curve $^{1}$ of the phase diagram, rather than when the much greater equilibrium concentration consistent with the $A e_{3}$ curve is achieved $[8,11]$. Given sufficient time at a high enough temperature, the retained austenite should therefore decompose into a mixture of ferrite and carbides. In this paper we undertake a detailed examination of the thermal stability of the microstructure given that many of the steels being developed either have to undergo transients into high-temperature regimes (for example during glavanising) or have to serve at moderately high temperatures over long periods of time.

It is acknowledged that previous studies [12-14] investigated the stability of the retained austenite and bainite mixtures, but these were conducted as continuous heating experiments, did not consider the dilatometric effect of the tempering of martensite present in the initial microstructure, and did not consider the stability of the remaining austenite on cooling to ambient temperature.

\section{Experimental Work}

An $\mathrm{Fe}-0.22 \mathrm{C}-3 \mathrm{Mn}-2.03 \mathrm{Si}$ wt\% alloy was prepared as a $20 \mathrm{~kg}$ vacuum induction melt from high purity base materials. The advantage of using this alloy is that a great deal is known about its transformation into a mixture of bainitic ferrite and retained austenite, including the $T_{0}$ curve and its validation $[15,16]$. The ingot was hot-forged and then hot-rolled to $25 \mathrm{~mm}$ square cross section bars. The alloy contains sufficient silicon to prevent the precipitation of cementite during transformation to bainite, and has sufficient hardenability to avoid other unwanted transformations during the course of cooling. Cylindrical samples, $12 \mathrm{~mm}$ long and $8 \mathrm{~mm}$ diameter, were machined from this material for heat treatment in a Thermecmaster thermomechanical simulator. The machine is capable of simultaneously monitoring the strain, load, time and temperature and is equipped with an environmental chamber which can be evacuated or filled with inert gas. The heat source is a radio frequency coil, and the temperature was measured using a $\mathrm{Pt} / \mathrm{Pt}-10 \mathrm{Rh}$ thermocouple spot welded to the sample.

Austenitization was carried out by heating the sample at $10^{\circ} \mathrm{C} \mathrm{s}^{-1}$ to $930^{\circ} \mathrm{C}$, where it was held for 30 min under vacuum. Samples were then cooled to $390^{\circ} \mathrm{C}$ at $10^{\circ} \mathrm{C} \mathrm{s}^{-1}$ using a jet of helium gas, for isothermal transformation to bainite for two hours in order to allow the maximum quantity of bainite consistent with the $T_{0}$ curve to form. The bainite and martensite-start temperatures ( $B_{S}$ and $M_{S}$ respectively) were calculated using the algorithms described elsewhere $[17,18]$. The heat treatment schedule is illustrated schematically in Fig 1.

The tempering temperature studied was $450^{\circ} \mathrm{C}$, which is higher than the $B_{S}$, with the tempering time ranging from $\frac{1}{2}$ to $5 \mathrm{~h}$. One sample was water quenched after austenitisation to establish the dimensional changes during subsequent tempering; this experiment helps to distinguish between

\footnotetext{
${ }^{1}$ The $T_{0}$ curve defines the locus of all points on a plot of temperature versus carbon concentration where austenite and ferrite of the same chemical composition have identical free energy. The $T_{0}^{\prime}$ curve accounts also for strain energy but the average carbon concentration at which the bainite reaction stops in the absence of carbide precipitation usually lies somewhere between $T_{0}$ and $T_{0}^{\prime}$ given the heterogeneous distribution of carbon in the austenite. A computer program and its associated documentation, for the calculation of such curves can be obtained freely from
}

http://www.msm.cam.ac.uk/map/steel/programs/mucg46-b.html 


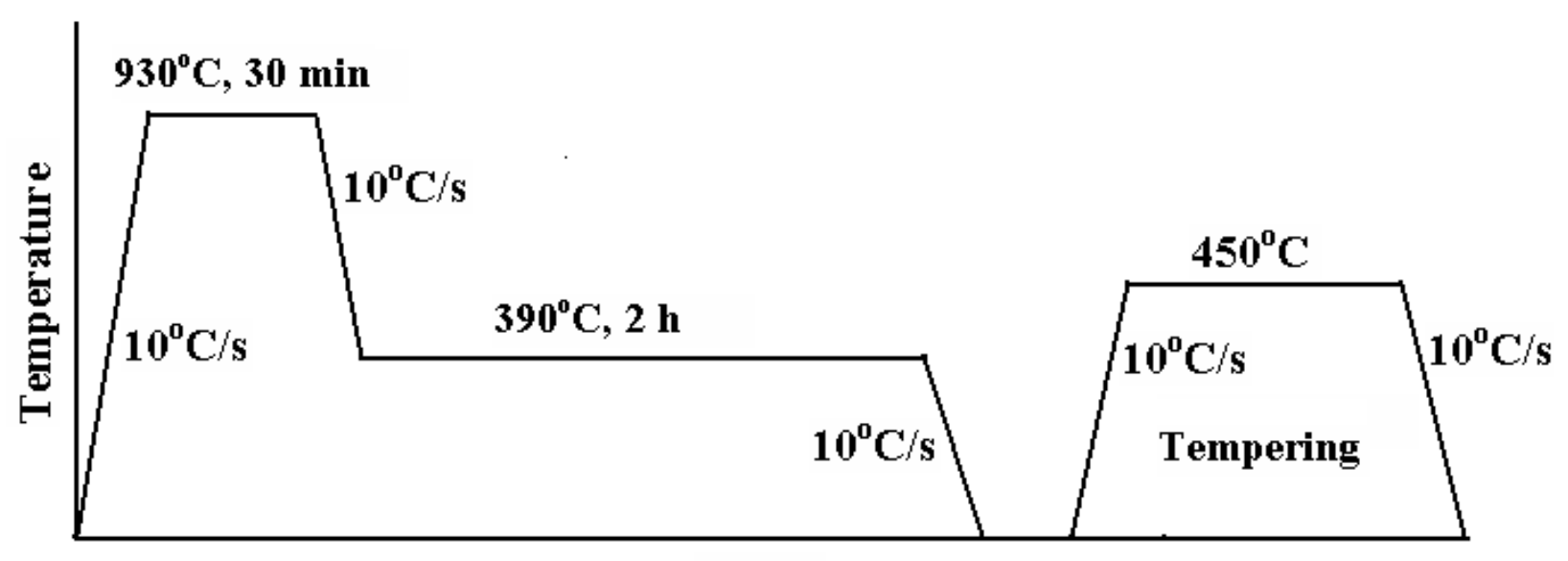

Time

Figure 1: The heat treatment schedule.

the changes that accompany the decomposition of austenite. Specimens for optical microscopy and transmission electron microscopy (TEM, JEOL 2000FX, 200 kV) were prepared using standard methods described elsewhere [19]. X-ray diffraction with $\mathrm{Cu} \mathrm{K}_{\alpha}$ radiation was conducted using continuous scanning at $0.05^{\circ} \mathrm{s}^{-1}$ over $2 \theta=30-150^{\circ}$. The volume fraction of retained austenite was determined using Rietveld refinement [20,21]. Specific step-scans over $2 \theta=36-52^{\circ}$ were carried out to characterise diffraction from the low-volume fractions of carbides expected on prolonged tempering.

\section{Transformation strain}

Assuming that phase changes in polycrystalline samples cause isotropic strains on a macroscopic scale, the linear and volume strains are related as follows:

$$
\frac{\Delta L}{L_{0}}=\frac{\Delta V}{3 V_{0}}
$$

where the subscript identifies the original dimensions. For austenite $(\gamma)$ decomposing into a mixture of ferrite $(\alpha)$ and cementite $(\theta)$,

$$
\frac{\Delta L}{L_{0}}=\frac{1}{3}\left[\frac{\left(2 V_{\alpha} a_{\alpha}^{3}+\frac{1}{3} V_{\theta} a_{\theta} b_{\theta} c_{\theta}\right)-V_{\gamma_{0}} a_{\gamma_{0}}^{3}}{V_{\gamma_{0}} a_{\gamma_{0}}^{3}}\right]
$$

where $V_{\gamma_{0}}$ is the initial volume fraction of austenite measured using $\mathrm{X}$-ray diffraction; $V_{\alpha}$ and $V_{\theta}$ are the volume fractions of ferrite and cementite respectively. $a_{\theta}, b_{\theta}$ and $c_{\theta}, a_{\alpha}$ and $a_{\gamma}$ are lattice parameters of the phases identified by the subscript, at the test temperature, calculated by correcting the values at room temperature with the appropriate expansion coefficient [22-24] 
(temperature in Kelvin):

$$
\begin{aligned}
& a_{\theta}=4.5165\left[1+\left\{6.0 \times 10^{-6}+3.0 \times 10^{-9}(T-273)+\right.\right. \\
& \left.\left.1.0 \times 10^{-11}(T-273)^{2}\right\}(T-298)\right] \quad \AA \\
& b_{\theta}=5.0837\left[1+\left\{6.0 \times 10^{-6}+3.0 \times 10^{-9}(T-273)+\right.\right. \\
& \left.\left.1.0 \times 10^{-11}(T-273)^{2}\right\}(T-298)\right] \quad \AA \\
& c_{\theta}=6.7475\left[1+\left\{6.0 \times 10^{-6}+3.0 \times 10^{-9}(T-273)+\right.\right. \\
& \left.\left.1.0 \times 10^{-11}(T-273)^{2}\right\}(T-298)\right] \quad \AA \\
& a_{\alpha}=2.8664+\frac{\left(a_{F e}-0.279 x_{\mathrm{C}}\right)^{2}\left(a_{\mathrm{Fe}}+2.496 x_{\mathrm{C}}\right)-a_{\mathrm{Fe}}^{3}}{3 a_{\mathrm{Fe}}^{2}}-0.03 x_{\mathrm{Si}}+ \\
& 0.06 x_{\mathrm{Mn}}+0.07 x_{\mathrm{Ni}}+0.31 x_{\mathrm{Mo}}+0.05 x_{\mathrm{Cr}}+0.096 x_{\mathrm{V}} \quad \AA \\
& a_{\gamma}=3.5780+0.033 w_{\mathrm{C}}+0.00095 w_{\mathrm{Mn}}-0.0002 w_{\mathrm{Ni}}+0.0006 w_{\mathrm{Cr}}+ \\
& 0.0056 w_{\mathrm{Al}}+0.0031 w_{\mathrm{Mo}}+0.0018 w_{\mathrm{V}} \quad \AA
\end{aligned}
$$

The carbon concentration of the ferrite is assumed to be $0.025 \mathrm{wt} \% ; x$ is the concentration in mole fraction and $w$ in weight fraction. The thermal expansion coefficients of ferrite and austenite considered in these calculation were $e_{\alpha}=1.244 \times 10^{-5} \mathrm{~K}^{-1}$ and $e_{\gamma}=2.065 \times 10^{-5} \mathrm{~K}^{-1}$ respectively.

The strain expected during the tempering of martensite is given by:

$$
\frac{\Delta L}{L_{0}}=\frac{1}{3}\left[\frac{\left(2 V_{\alpha} a_{\alpha}^{3}+\frac{1}{3} V_{\theta} a_{\theta} b_{\theta} c_{\theta}\right)-2 V_{\alpha^{\prime}} a_{\alpha^{\prime}}^{2} c_{\alpha^{\prime}}}{2 V_{\alpha^{\prime}} a_{\alpha^{\prime}}^{2} c_{\alpha^{\prime}}}\right]
$$

where $V_{\alpha^{\prime}}$ is the initial volume fraction of martensite and $a_{\alpha^{\prime}}$ and $c_{\alpha^{\prime}}$ are lattice parameters of martensite, measured using $\mathrm{X}$-ray diffraction.

\section{Results}

Fig. 2 shows the bainite sheaves in a matrix of martensite and retained austenite (grey-etching blocks), obtained by isothermal transformation at $390^{\circ} \mathrm{C}$ for $2 \mathrm{~h}$. It is difficult to distinguish the martensite from the retained austenite, but some martensite must form during cooling from $390^{\circ} \mathrm{C}$ to room temperature. The amount of austenite remaining at the isothermal transformation temperature can be calculated using the $T_{0}$ curve of the phase diagram [25], where this curve represents the locus of all points on a plot of temperature versus carbon concentration where austenite and ferrite of the identical composition have the same Gibbs free energy. The curve determines the limiting concentration of carbon in the austenite at the point where the bainite reaction ceases, so by applying the lever rule to the $T_{0}$ curve, the quantity of residual austenite was estimated as $V_{\gamma}^{390}=0.32$ for transformation at $390^{\circ} \mathrm{C}$. Some of this may decompose to martensite, and this quantity can be estimated by applying the Koistinen and Marburger equation [26]:

$$
1-V_{\alpha^{\prime}}=\exp \left[-0.011\left(M_{S}-T_{Q}\right)\right]
$$


where $M_{S}$ and $T_{Q}=20^{\circ} \mathrm{C}$ represent the martensite-start and room temperatures respectively. $M_{S}$ is calculated [18] for the composition of the carbon-enriched austenite left untransformed at $390^{\circ} \mathrm{C}$. The fraction of martensite was in this way calculated to be $V_{\alpha^{\prime}}^{25}=0.185$, thus leaving a fraction $V_{\gamma}^{25}=0.135$ of austenite retained to room temperature. The thickness of the bainite plates was measured as described in $[27,28]$ and found to $300 \pm 22 \mathrm{~nm}$.

\subsection{Microstructural Evolution During Tempering}

Tempering at $450^{\circ} \mathrm{C}$ leads to significant changes in the optical microstructure (Fig. 3) with the development of dark-etching regions in what was previously the blocky areas in the untempered sample. The dark regions grew in extent as the tempering time was increased. Higher resolution micrographs are presented in Fig. 4a,b which reveal clearly that the dark regions are tempered martensite. There is, of course the possibility that some features identified as tempered martensite are due to the decomposition of retained austenite by a diffusional mechanism into a mixture of ferrite and carbides, but Fig. 4c shows an experiment in which tempering was conducted at a temperature of $250^{\circ} \mathrm{C}$, which is too low to permit the necessary diffusion. The observed structure in the blocky regions is identical to that of the samples tempered at $450^{\circ} \mathrm{C}$, showing that the interpretation related to the tempering of martensite is correct.

Fig. 5 shows the change in Vickers hardness as a function of the tempering time. The decrease in hardness due to tempering is minimal, about $30 \mathrm{HV}$ over a period of $5 \mathrm{~h}$ at $450^{\circ} \mathrm{C}$. The extent and rate of change of properties during tempering is expected to be small for bainite because there is little excess carbon in solution in the ferrite. The microstructure in effect tempers during the course of transformation with the partitioning of excess carbon into the residual austenite [29].

\subsection{Dilatometric Analysis}

The metallographic observations already described indicate that the initial changes are due to the tempering of martensite, followed by the decomposition of retained austenite into a mixture of ferrite and cementite. The former process should lead to a contraction as supersaturated martensite precipitates cementite, whereas the latter should be accompanied by an expansion of the sample at constant temperature, section 3, [30]. Figs 6a-c show that the net tempering strain is negative for a time up to about 1 hour at temperature, followed by an increase in specimen dimensions. There was a increase in dimension as tempering progresses.

To further confirm this interpretation, a sample was tempered at $250^{\circ} \mathrm{C}$, where austenite decomposition is most unlikely; Fig. 6d shows that the decrease in strain is comparable to that obtained at the higher tempering temperature, proving that the contraction is due to the tempering of martensite. A sample quenched from the austenitising temperature in order to produce a fully martensitic sample was tempered, Fig. 6e; a larger contraction consistent with the fact that the starting microstructure is just martensite, was observed, proving the role of martensite tempering in causing a contraction in sample dimensions.

The subsequent expansion seen in Fig. 6c virtually compensates for the contraction accompanying 


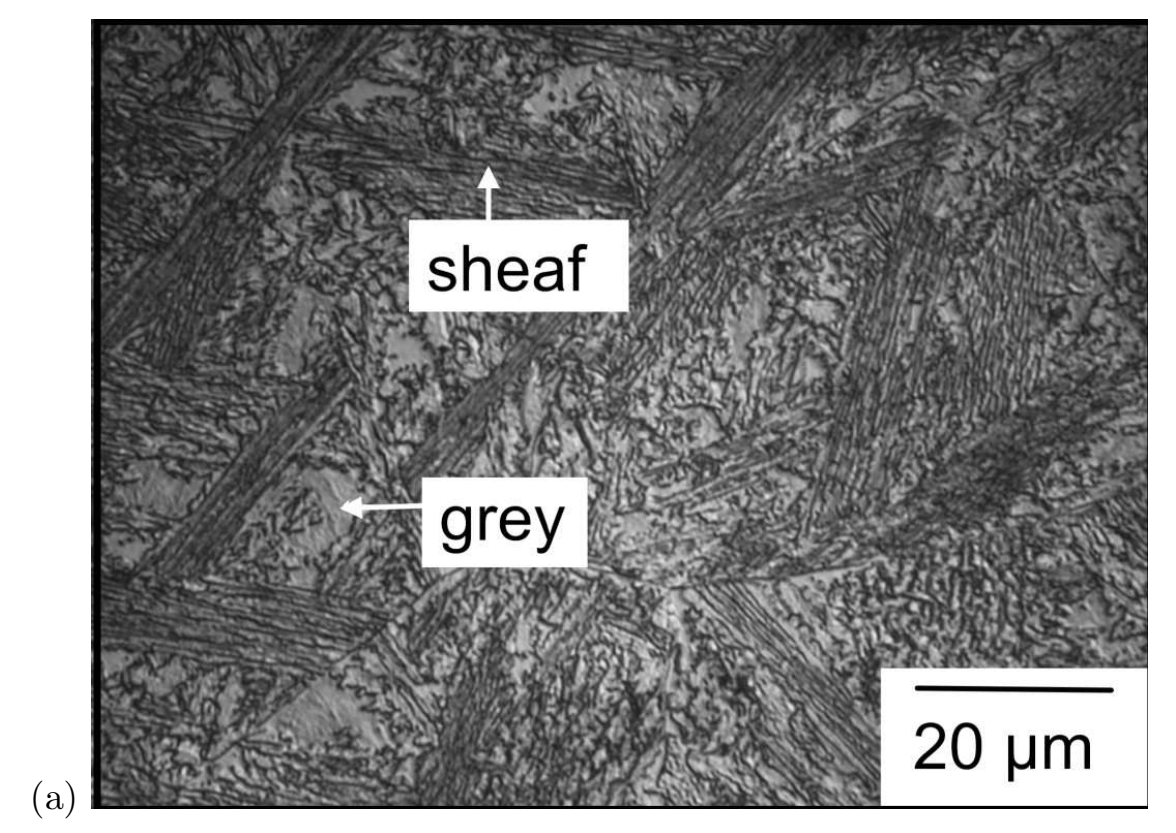

(a)

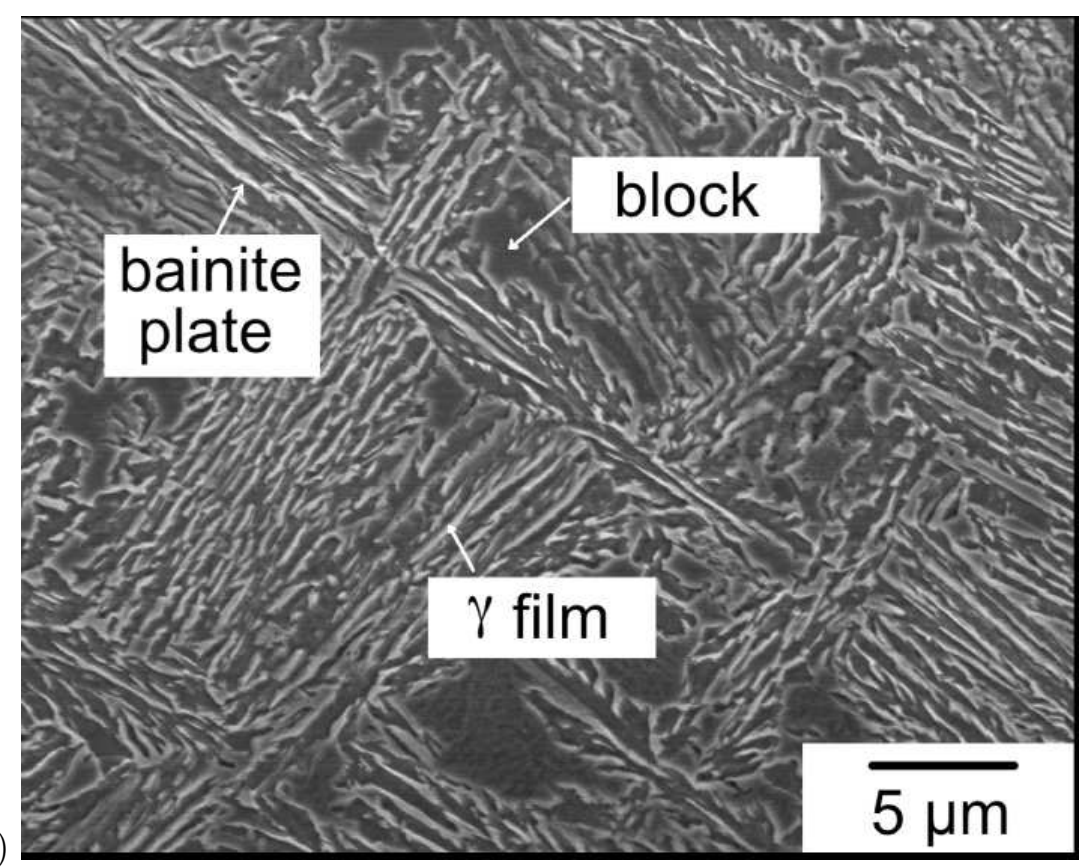

Figure 2: (a) Optical micrograph showing bainite sheaves embedded in a residue of martensite and retained austenite (grey). The steel was transformed isothermally at $390^{\circ} \mathrm{C}$ for $2 \mathrm{~h}$. Calculations indicate that the volume fractions of bainitic ferrite, retained austenite and martensite are 0.68, 0.18 and 0.14 respectively. (b) Corresponding scanning electron micrograph. 

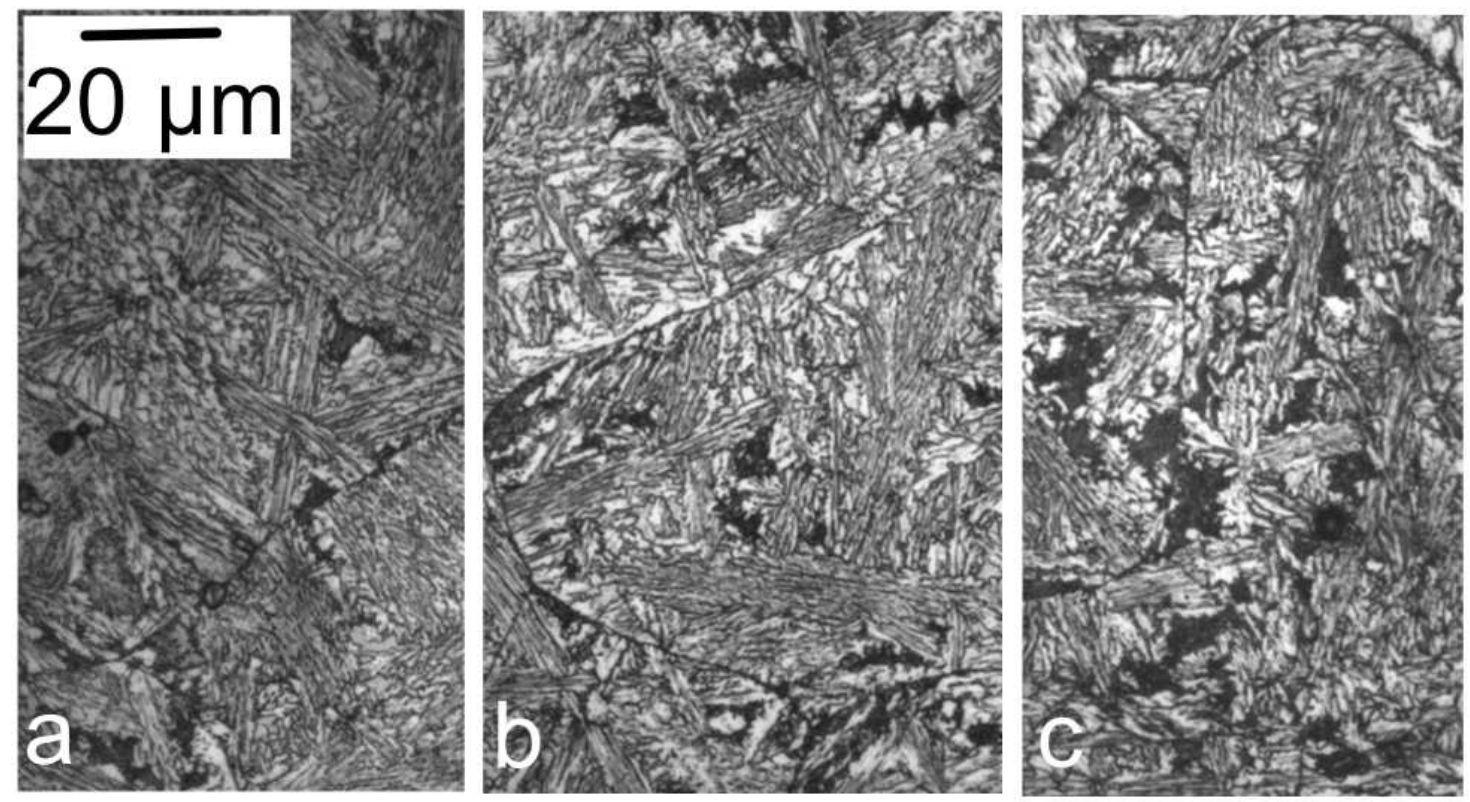

Figure 3: Optical micrographs of sample tempered at $450^{\circ} \mathrm{C}$ for (a) $30 \mathrm{~min}$, (b) $1 \mathrm{~h}$ and (c) $2 \mathrm{~h}$.

the tempering of martensite, leaving the sample essentially unchanged in dimensions following prolonged tempering.

The strain for the austenite decomposition calculated using equation 2 decreased as the tempering temperature was raised, as illustrated in Fig. 7a. The measured result (Fig. 6c) is very much consitant with the calculated result. The strain due to tempering of martensite calculated using equation 6 taking account of same amount of martensite formed after isothermal transformation and the calculated strain is close to the experimental result at $250^{\circ} \mathrm{C}$ as depicted in $6 \mathrm{~d}$. In case of fully martensitic sample the calculated strain ( $7 \mathrm{c}$ ) is slightly deviated from the experimental value( $6 \mathrm{~d}$ ) because the calculated strain totally depends on the lattice parameter of martensite.

\subsection{Quantitative Determination of Phase Fractions}

The volume fractions of austenite retained following isothermal transformation and tempering were measured using $\mathrm{X}$-ray diffraction. Fig. 8 and Table 1 show the dramatic reduction in retained austenite content even after tempering at $450^{\circ} \mathrm{C}$ for 30 minutes. In contrast, the tempering at $250^{\circ} \mathrm{C}$ causes no change in the retained austenite content, Fig. 9a. Prolonged tempering which leads to the decomposition of austenite confirms the emergence of cementite, Fig. 9b.

The carbon content of the retained austenite after the isothermal transformation to bainitic ferrite was calculated using the $T_{0}$ curve temperature to be $0.7 \mathrm{wt} \%$ whereas the carbon content of retained austenite measured from the X-ray diffraction was $0.67 \mathrm{wt} \%$. The volume fraction of retained austenite calculated using equation 7 was 0.135 and this matches with the measured value from $\mathrm{X}$-ray diffraction (Table 1). 
(a)

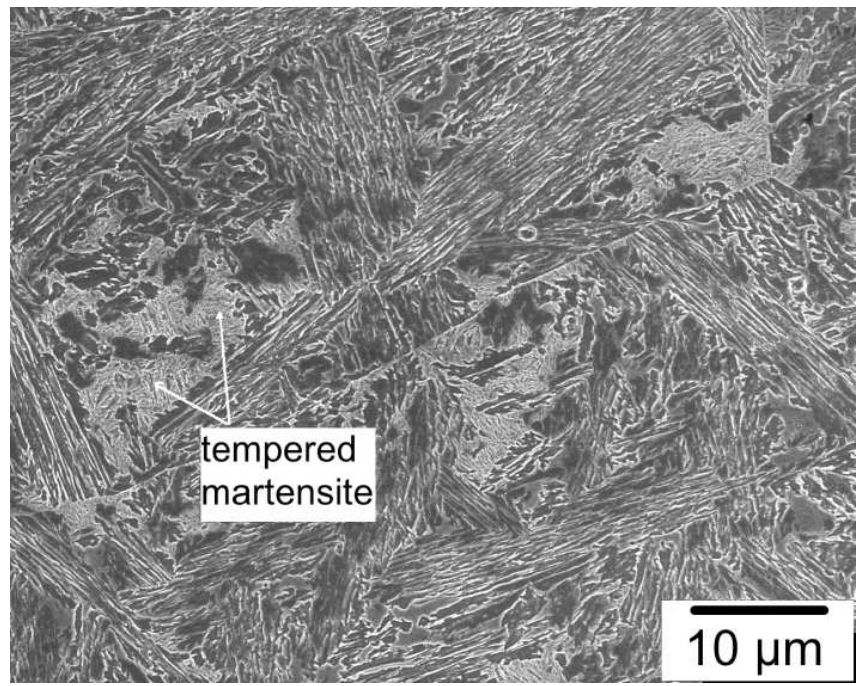

(b)

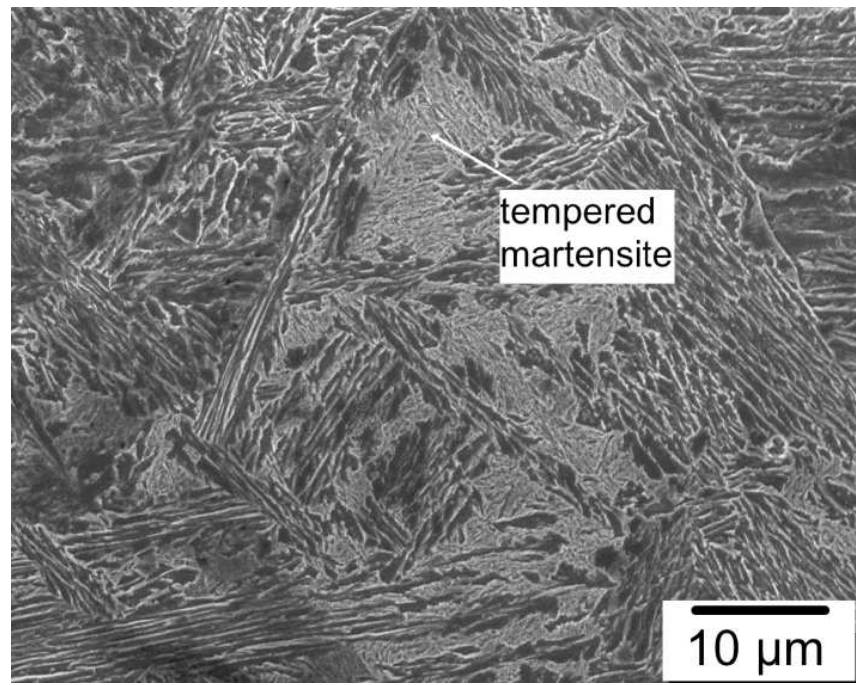

(c)

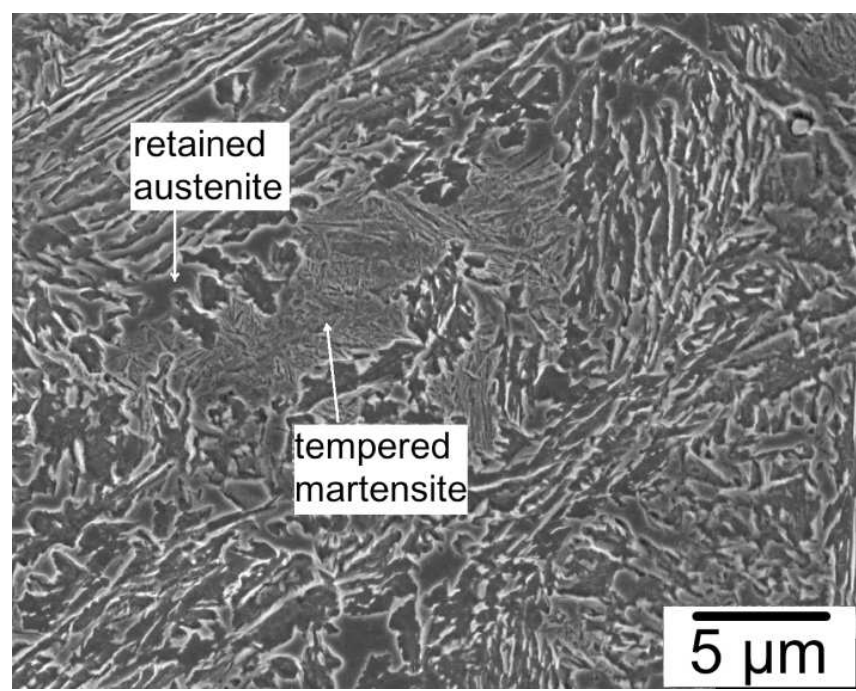

Figure 4: Scanning electron micrographs of samples transformed at $390^{\circ} \mathrm{C}$ for $2 \mathrm{~h}$, and then tempered at (a) $450^{\circ} \mathrm{C}$ for $1 \mathrm{~h}$, (b) $450^{\circ} \mathrm{C}$ for $2 \mathrm{~h}$ and (c) $250^{\circ} \mathrm{C}$ for $5 \mathrm{~h}$. 


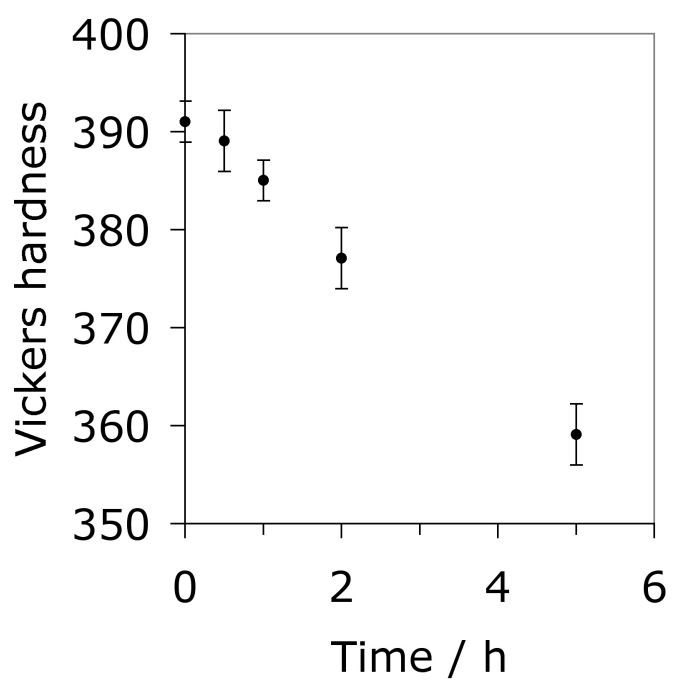

Figure 5: Variation of hardness (measured using $30 \mathrm{~kg}$ load) with tempering time at $450^{\circ} \mathrm{C}$.

\begin{tabular}{cccccc}
\hline$t / \min$ & $T /{ }^{\circ} \mathrm{C}$ & $\gamma / \%$ & $\alpha / \%$ & $a_{\gamma} / \AA$ & $a_{\alpha} / \AA$ \\
\hline 0 & - & 13.3 & 86.7 & 3.6031 & 2.8667 \\
30 & 450 & 4.2 & 95.8 & 3.5959 & 2.8671 \\
60 & 450 & 1.8 & 98.2 & 3.5888 & 2.866 \\
120 & 450 & 1.3 & 98.7 & 3.5880 & 2.8654 \\
300 & 450 & 0 & 100 & $\mathrm{NA}$ & 2.8648 \\
300 & 250 & 12.9 & 87.1 & 3.6042 & 2.8665 \\
\hline
\end{tabular}

Table 1: Summary of the X-ray diffraction analysis.

The change in the carbon content of the retained austenite during tempering, determined from the measured lattice parameter of retained austenite, is presented in Fig. 10. The fact that the concentration decreases even on tempering for $30 \mathrm{~min}$ implies that carbide precipitation from the austenite is quite rapid. Such carbides can only be detected using transmission electron microscopy, as reported later in this paper. The lattice parameter of "ferrite" is more difficult to interpret because it reflects that of both martensite and bainitic ferrite, but the trend is consistent with the tempering of martensite. Precipitation of cementite from martensite or bainitic ferrite would lead to a decrease in their lattice parameters; the somewhat slow decrease during tempering at $450^{\circ} \mathrm{C}$ is a known phenomenon [27] associated with the fact that carbon tends to be trapped at dislocations, where they have a lower energy than in the cementite lattice [31].

\subsection{Transmission Microscopy}

Detailed observations revealed that fine carbide particles precipitated at all the time periods studied for tempering at $450^{\circ} \mathrm{C}$. Intensive electron microscopy study were carried out in order to identify the type of carbides. Electron diffraction pattern in Fig. 11 taken from the tempered retained austenite 

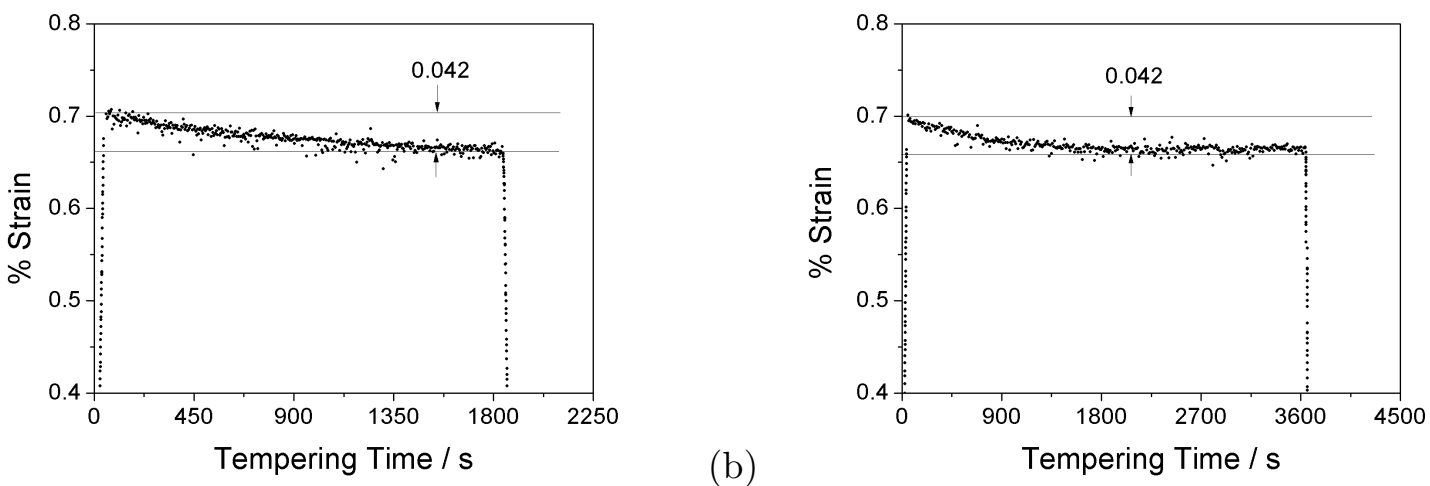

(a)

(b)
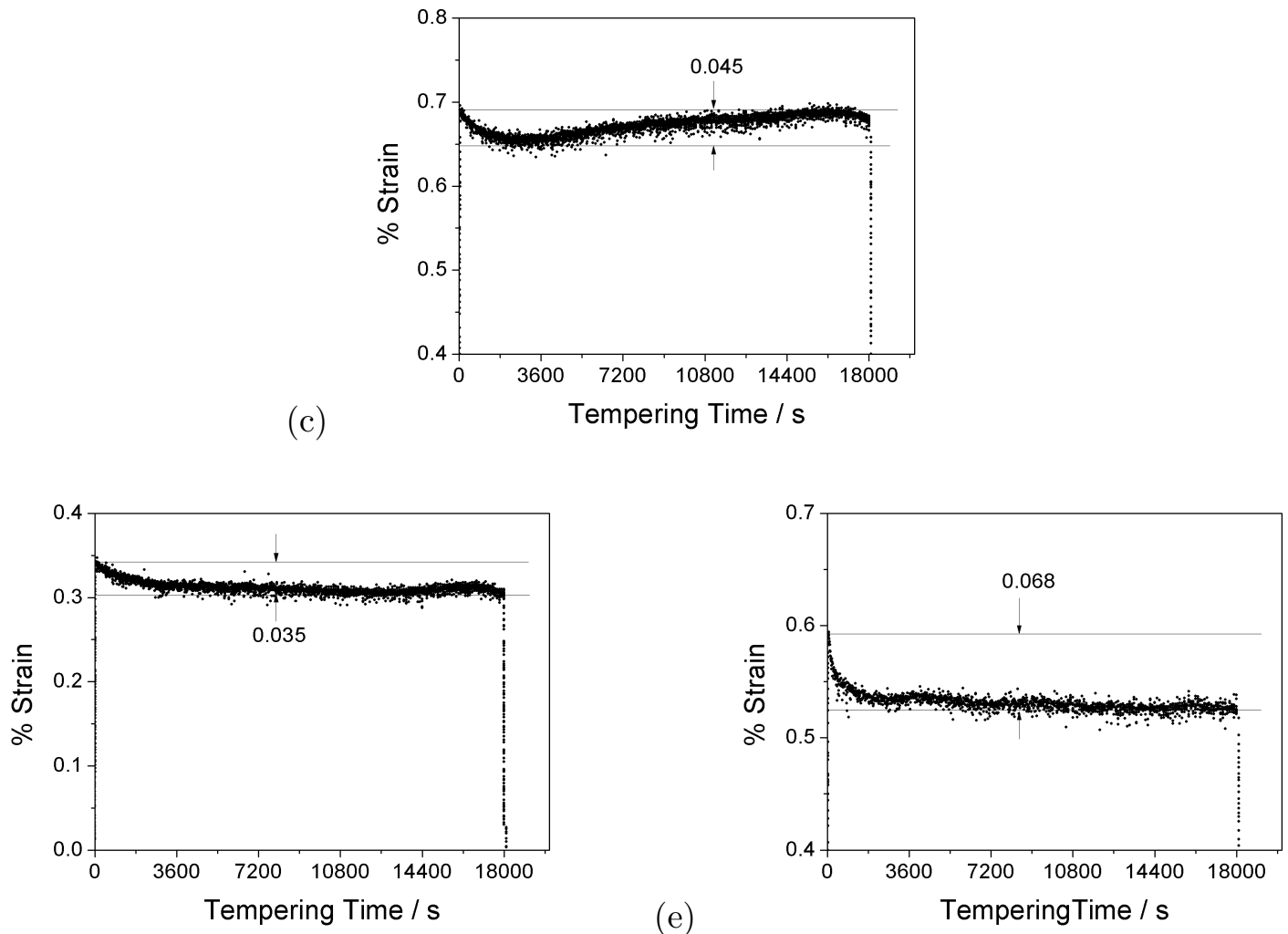

Figure 6: Dilatometric curves obtained during tempering at $450^{\circ} \mathrm{C}$ for tempering times of (a) 30 min, (b) $1 \mathrm{~h}$ and (c) $5 \mathrm{~h}$. (d) Tempered at $250^{\circ} \mathrm{C}, 5 \mathrm{~h}$. (e) Dilatation curve during tempering of a fully martensitic sample tempered at $450^{\circ} \mathrm{C}$. 


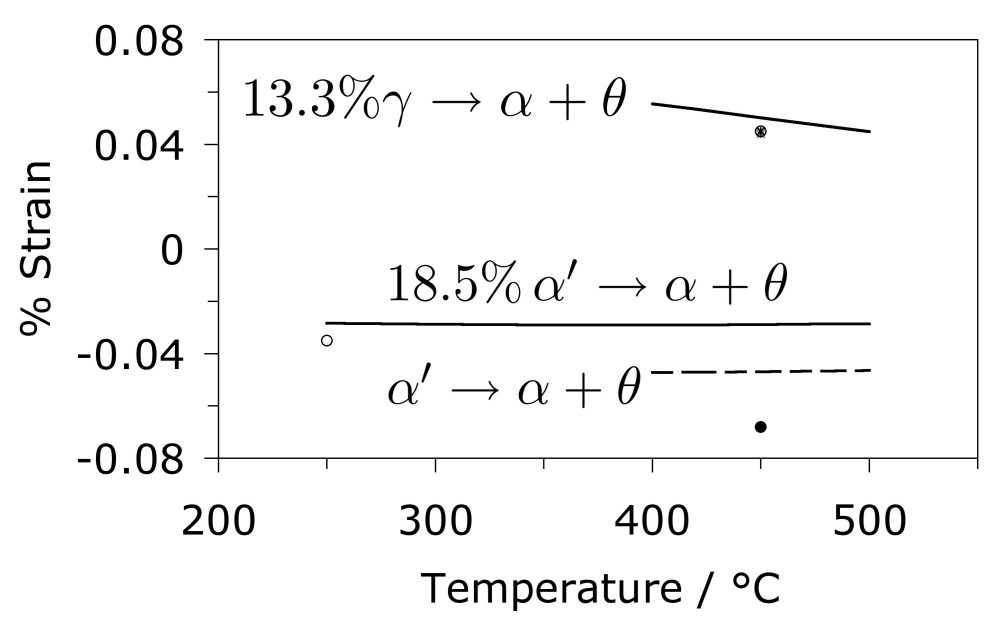

Figure 7: The calculated strains for the decomposition of a microstructure containing $13.3 \%$ of retained austenite containing $0.67 \mathrm{wt} \% \mathrm{C}$, due to the tempering of a microstructure containing $18.5 \%$ martensite containing $0.67 \mathrm{wt} \% \mathrm{C}$, and of a fully martensitic sample containing $0.22 \mathrm{wt} \%$ C. The points near each line represent experimental measurements.

film in a sample after tempering at $450^{\circ} \mathrm{C}$ for $2 \mathrm{~h}$ reveals the presence of cementite carbide. The carbides have been observed to precipitate at the interface between ferrite and retained austenite.

\subsection{Stability of Retained Austenite}

Transmission electron microscopy of samples which were tempered at $450^{\circ} \mathrm{C}$ and then cooled to ambient temperature revealed both tempered and untempered martensite, which could be distinguished easily by checking for the presence or absence of cementite precipitation. An example of untempered martensite is illustrated in Fig. 12, illustrating the twinned martensite typical of transformation from high-carbon austenite. It is evident that tempering destabilises the austenite due to the local reduction in carbon concentration following the precipitation of cementite, so that some of it transforms into untempered martensite on cooling.

\section{Discussion}

The characterisation experiments all indicate a sequence during heat treatment at $450^{\circ} \mathrm{C}$, in which martensite tempers relatively rapidly, but followed by the decomposition of the austenite into a mixture of cementite and ferrite. The initial stage in the decomposition of the austenite is the precipitation of cementite, with the formation of ferrite occurring some one hour after the beginning of the tempering reaction.

It has been possible in the dilatometric experiments to clearly separate the contraction due to the tempering of martensite, and the expansion due to the formation of cementite and ferrite from austenite. The calculated strain due to austenite decomposition using equation 2 is found to be $0.0502 \%$ for an initial austenite fraction of 0.133 , which is consistent with the measured strain during tempering at $450^{\circ} \mathrm{C}$ (Fig. 6).

For martensite tempering the calculated strain using equation 6 for a fully martensitic sample was 


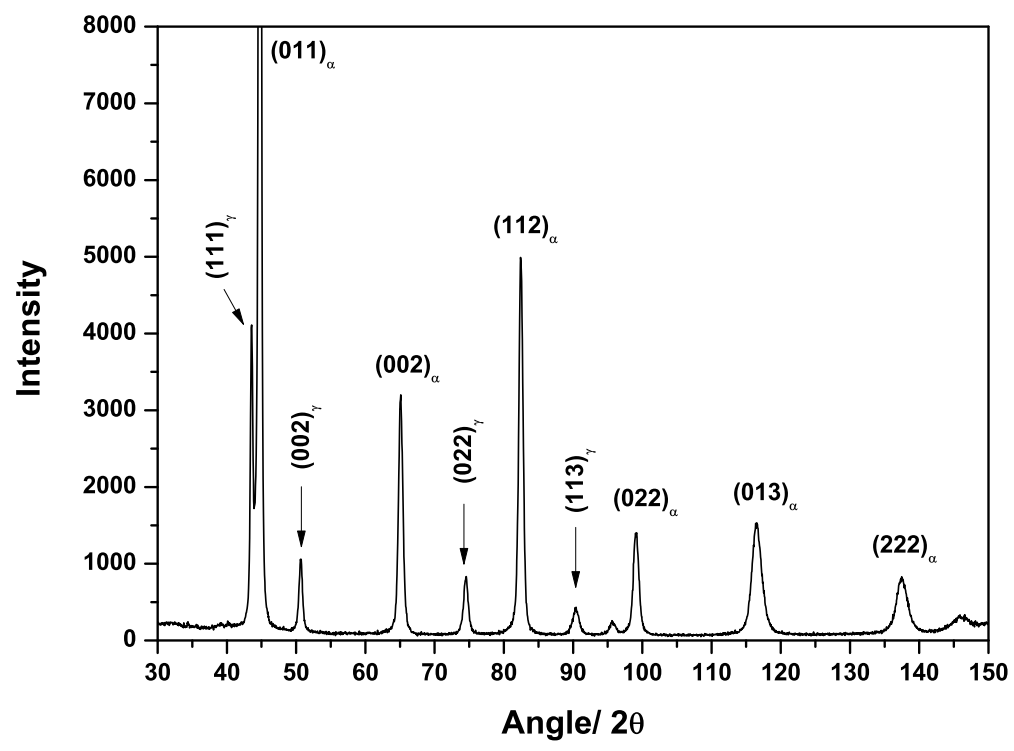

(a)

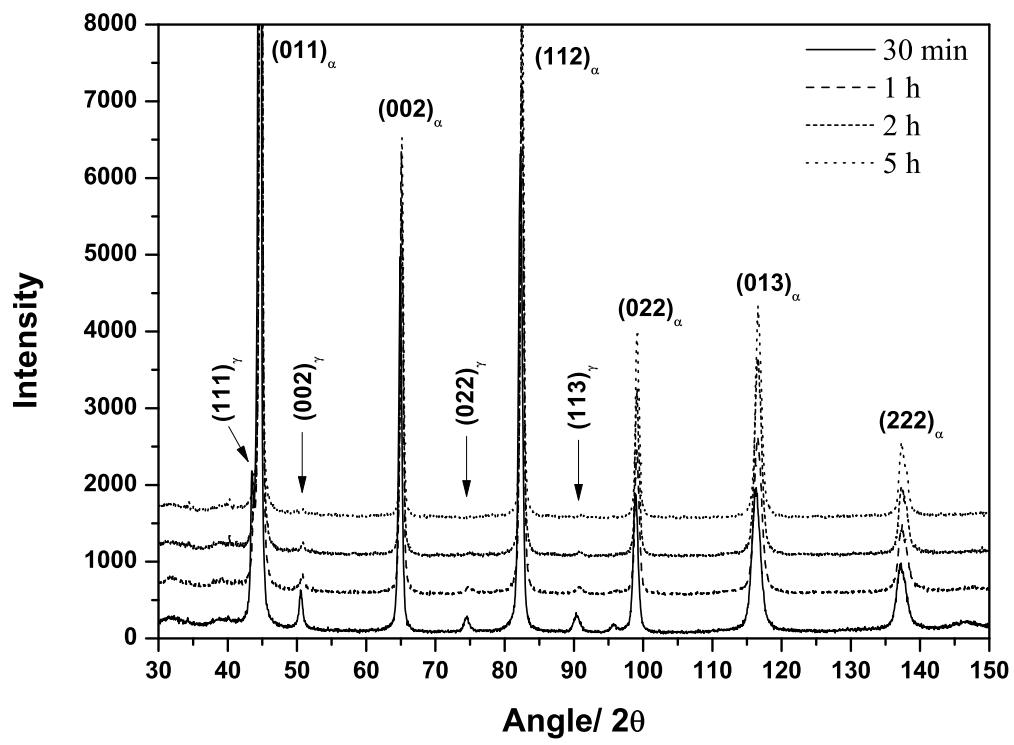

(b)

Figure 8: X-ray diffraction experiments. (a) Following isothermal transformation at $390^{\circ} \mathrm{C}$. (b) Isothermal transformation followed by tempering at $450^{\circ} \mathrm{C}$. 


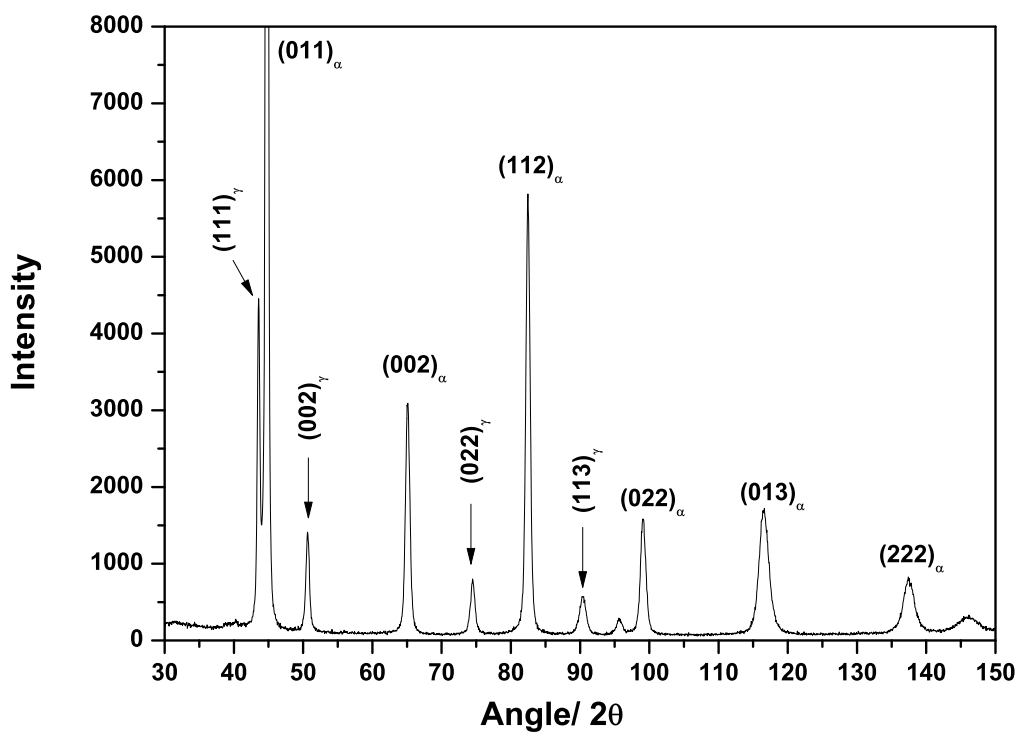

(a)

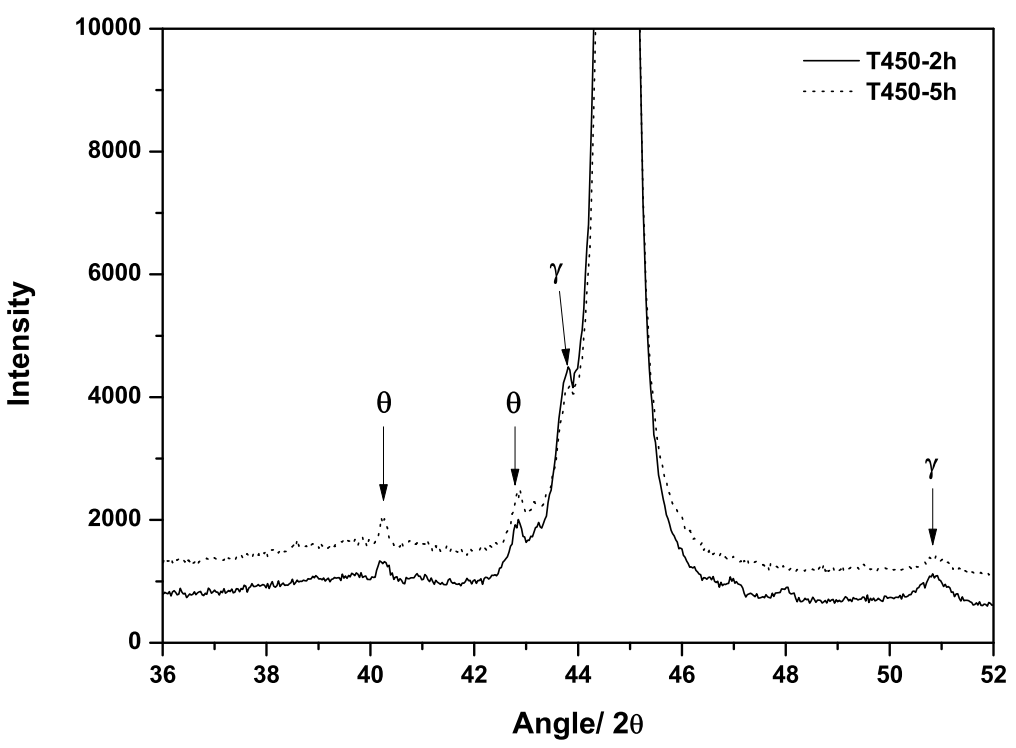

(b)

Figure 9: (a) $\mathrm{X}$ - ray diffraction pattern after tempering for $5 \mathrm{~h}$ at $250^{\circ} \mathrm{C}$. (b) Diffraction patterns focusing on low $\theta$, after tempering for $2 \mathrm{~h}$ and $5 \mathrm{~h}$ at $450^{\circ} \mathrm{C}$. 


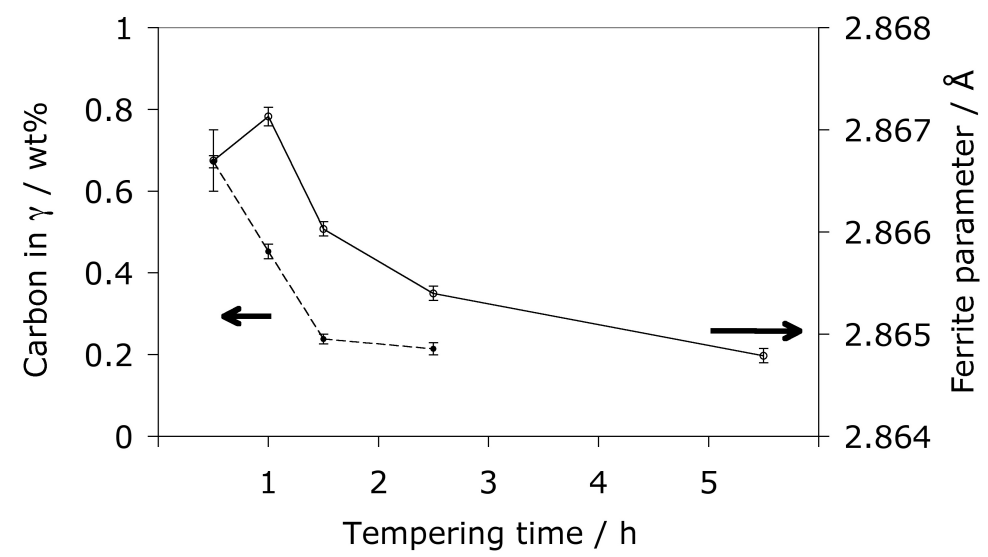

Figure 10: Carbon concentration in austenite and lattice parameter of ferrite as a function of the tempering time at $450^{\circ} \mathrm{C}$.

$0.047 \%$ whereas that determined experimentally was closer to $0.068 \%$ as shown in Figs. 6e. The calculation is, however, very sensitive to the initial and final lattice parameters of the martensite. In the case of Tempering at $250^{\circ} \mathrm{C}$, where the volume fraction of initial martensite was calculated using the thermodynamic model to be $V_{\alpha^{\prime}}^{25}=0.185$, the calculated percent strain was $0.035 \%$ is close to the measured strain was $0.0285 \%$ (Fig. $7 \mathrm{~b}$ ).

An important outcome from the present work is that the early stages of tempering (time less than one hour) do not lead to ferrite formation as indicated by the contraction evident in the dilatometric curves. Nevertheless, tempering leads to a dramatic decrease in the amount of retained austenite measured on the tempered samples at room temperature. This is because of the precipitation of minute quantities of cementite from the austenite, which leads to a decrease in its carbon concentration and hence the forming of untempered martensite on cooling to ambient temperature. This untempered martensite has been unambiguously identified using transmission electron microscopy.

Finally, it is notable that Cameron in 1956 [32] noted that in an EN40C steel containing retained austenite, tempering followed by cooling to room temperature resulted in an increase in hardness. He described this as the "conditioning" of the austenite, and concluded that tempering resulted in a reduction in the carbon content of the austenite so that it transformed on cooling, thus leading to the increase in hardness. We have presented here evidence for the detailed mechanism but the conclusions reached in the present work are essentially identical.

\section{Summary}

The tempering behaviour of a mixture of bainitic ferrite, retained austenite and martensite has been studied using a variety of characterisation techniques. The tempering experiments were carried out mostly at a temperature above the isothermal transformation temperature used to generate the original microstructure. A clear and novel picture has emerged for these conditions, on the events leading to the loss of stability of retained austenite present prior to tempering.

It appears that for the circumstances studied, there are two separable stages, the first involving the tempering of martensite and the precipitation of minute quantities of cementite from super- 


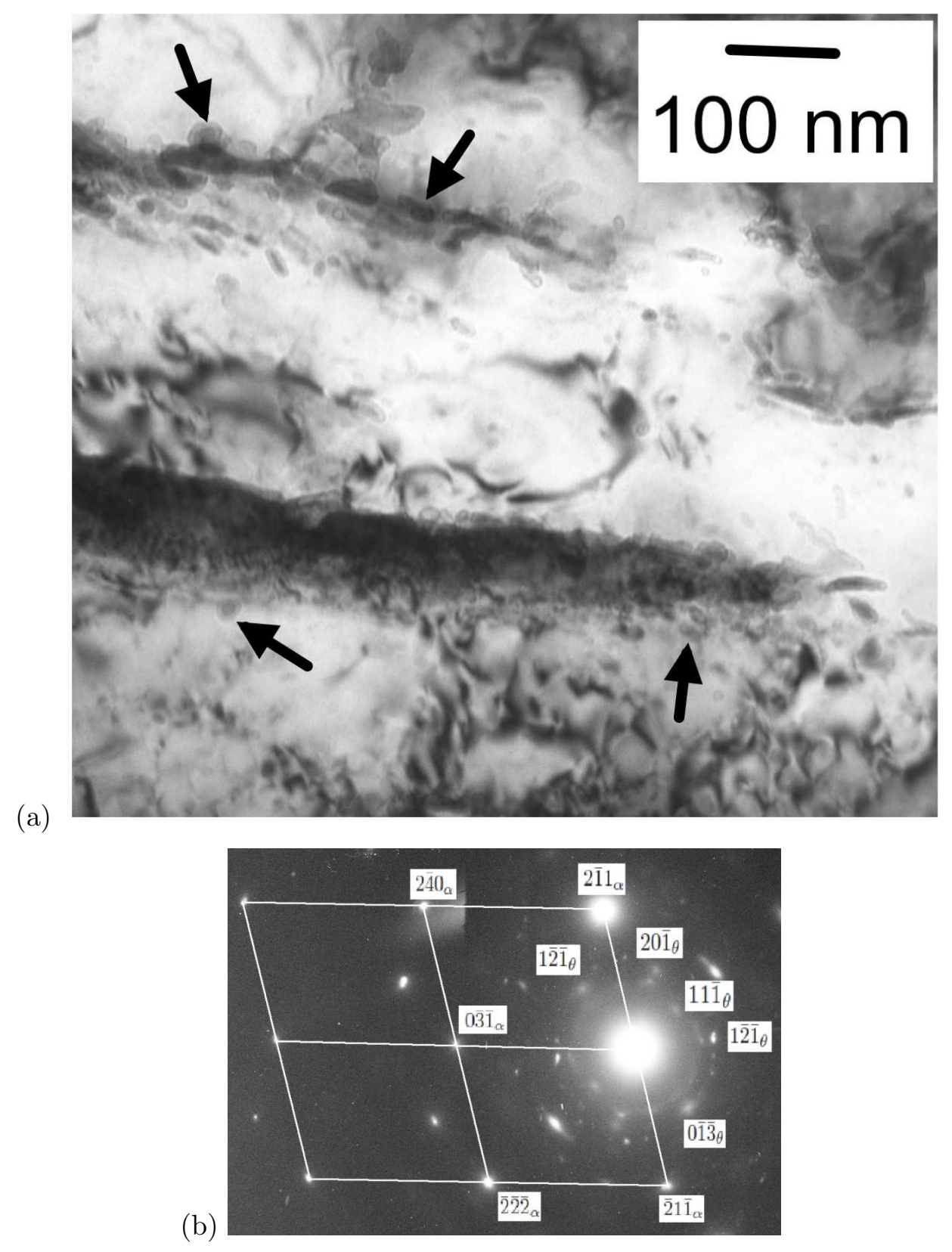

Figure 11: (a) Transmission electron micrograph, with the lower half showing austenite containing containing fine cementite particles (arrowed) following tempering at $450^{\circ} \mathrm{C}$ for $2 \mathrm{~h}$. The upper half shows a thinner austenite film which has decomposed. (b) Electron diffraction pattern obtained from the tempered austenite region. 

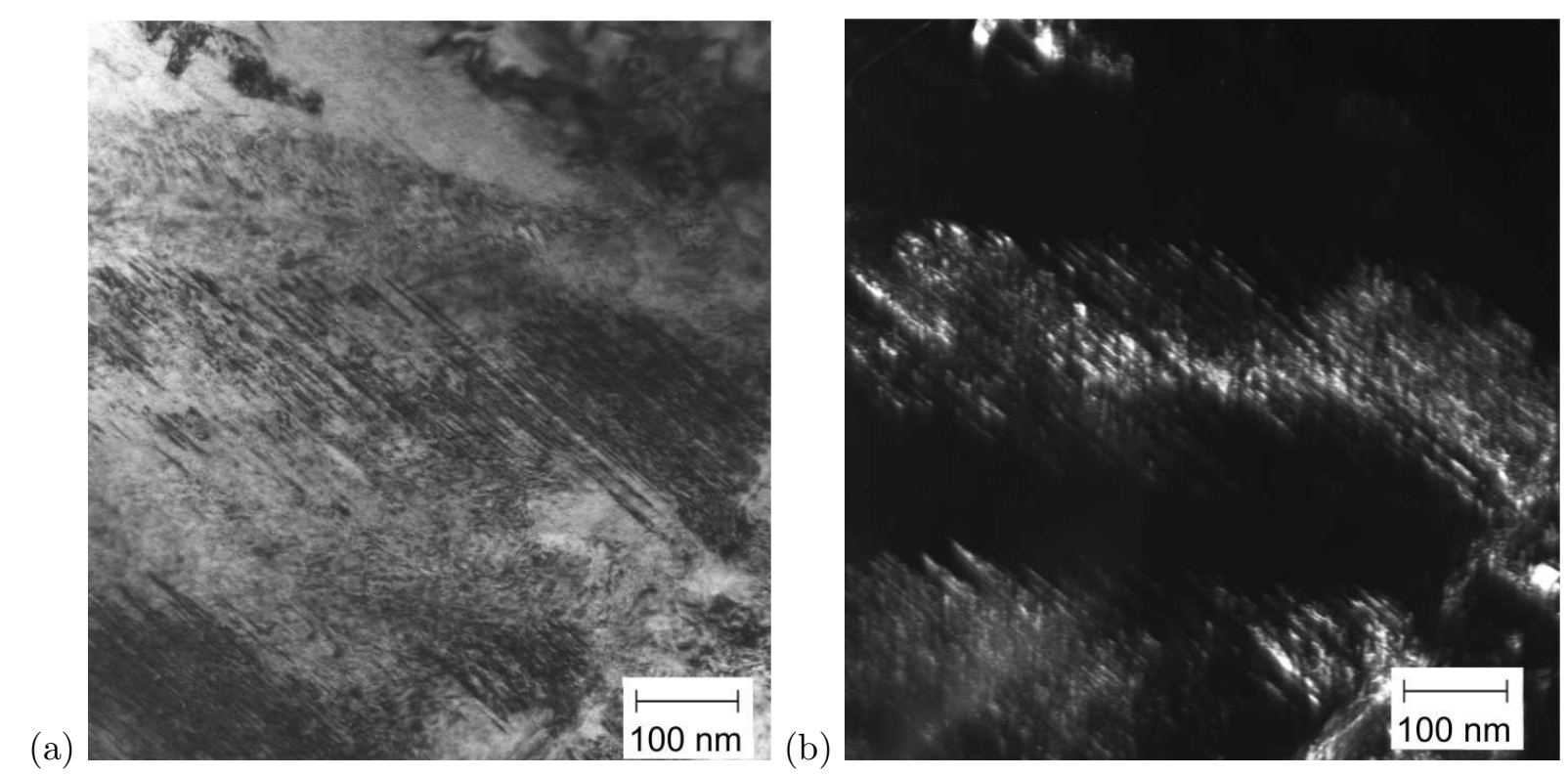

Figure 12: Bright and dark field transmission electron microscope images of untempered martensite (showing twins) in sample tempered at $450^{\circ} \mathrm{C}$ for $1 \mathrm{~h}$

saturated austenite. This latter process makes the austenite sufficiently unstable to martensitic transformation on cooling, leading to a dramatic loss in the quantity of retained austenite measured at room temperature. The second stage involves the transformation of the austenite at the tempering temperature into ferrite and further quantities of carbides.

\section{Acknowledgements}

The authors are grateful to the Cambridge Commonwealth Trust for funding this work.

\section{References}

[1] W. W. Gerberich, G. Thomas, E. R. Parker, V. F. Zackay: Metastable austenites: decomposition and strength: in: Second International Conference on Strength of Metals and Alloys: ASM International, Ohio, USA, 1970: pp. 894-899.

[2] O. Matsumura, Y. Sakuma, H. Takechi: Transactions of the Iron and Steel Institute of Japan 27 (1987) 570-579.

[3] J. Deliry: Memoires Scientifiques Rev. Metallurg. 62 (1965) 527-550.

[4] J. Pomey: Memoires Scientifiques Rev. Metallurg. 63 (1966) 507-532.

[5] E. Kozeschnik, H. K. D. H. Bhadeshia: Materials Science and Technology 24 (2008) 343-347.

[6] E. R. Parker: Metallurgical Transactions A 8A (1977) 1025-1042. 
[7] E. Dorazil, B. Barta, E. Munsterova, L. Stransky, A. Huvar: AFS International Cast Metals Journal 22 (1982) 52-62.

[8] P. J. Jacques: Current Opinion in Solid State and Materials Science 8 (2004) 259-265.

[9] B. DeCooman: Current Opinion in Solid State and Materials Science 8 (2004) 285-303.

[10] H. K. D. H. Bhadeshia: Materials Science Forum 500-501 (2005) 63-74.

[11] P. G. Self, H. K. D. H. Bhadeshia, W. M. Stobbs: Ultramicroscopy 6 (1981) 29-40.

[12] J. R. Yang, H. K. D. H. Bhadeshia: The bainite to austenite transformation: in: G. W. Lorimer (Ed.), Phase Transformations '87: 1988: pp. 365-373.

[13] J. R. Yang, H. K. D. H. Bhadeshia: Materials Science \& Engineering A 131 (1991) 99-113.

[14] F. G. Caballero, C. Garcia-Mateo, C. G. de Andrés: Materials Transactions 46 (2005) 581-586.

[15] H. K. D. H. Bhadeshia, D. V. Edmonds: Metal Science 17 (1983) 411-419.

[16] H. K. D. H. Bhadeshia, D. V. Edmonds: Metal Science 17 (1983) 420-425.

[17] H. K. D. H. Bhadeshia: Acta Metallurgica 29 (1981) 1117-1130.

[18] H. K. D. H. Bhadeshia: Metal Science 15 (1981) 178-150.

[19] H. K. D. H. Bhadeshia, D. V. Edmonds: Metallurgical Transactions A 10A (1979) 895-907.

[20] H. M. Rietveld: Journal of Applied Crystallography 2 (1969) 65-71.

[21] L. B. McCusker, R. B. V. Dreele, D. E. Cox, D. Louer, P. Scardi: J. Appl. Cryst. 32 (1999) $36-50$.

[22] H. Stuart, N. Rindley: Journal of the Iron and Steel Institute 204 (1966) 711-717.

[23] D. J. Dyson, B. Holmes: Journal of the Iron and Steel Institute 208 (1970) 469-474.

[24] H. K. D. H. Bhadeshia, S. A. David, J. M. Vitek, R. W. Reed: Materials Science and Technology 7 (1991) 686-698.

[25] H. K. D. H. Bhadeshia, D. V. Edmonds: Acta Metallurgica 28 (1980) 1265-1273.

[26] D. P. Koistinen, R. E. Marburger: Acta Metallurgica 7 (1959) 59-60.

[27] M. Peet, C. Garcia-Mateo, F. G. Caballero, H. K. D. H. Bhadeshia: Materials Science and Technology 20 (2004) 814-818.

[28] R. T. DeHoff, F. N. Rhines: Quantitative Microscopy: McGraw Hill, New York, 1968.

[29] H. K. D. H. Bhadeshia: Bainite in Steels, 2nd edition: Institute of Materials, London, 2001.

[30] L. Cheng, C. M. Brakman, B. M. Korevaar, E. J. Mittemeijer: Metallurgical \& Materials Transactions A 19 (1988) 2415-2426.

[31] D. Kalish, M. Cohen: Materials Science and Engineering 6 (1970) 156-166.

[32] J. A. Cameron: Journal of the Iron and Steel Institute 194 (1956) 260-267. 